Volume 15

Issue 3 Mass Atrocity and Collective Healing

Article 8

$12-21-2021$

\title{
Collective Healing: Towards a Conceptual Framework
}

Garrett Thomson

College of Wooster and GHFP Research Institute

Follow this and additional works at: https://digitalcommons.usf.edu/gsp

\section{Recommended Citation}

Thomson, Garrett (2021) "Collective Healing: Towards a Conceptual Framework," Genocide Studies and Prevention: An International Journal: Vol. 15: Iss. 3: 33-48.

DOI:

https://doi.org/10.5038/1911-9933.15.3.1843

Available at: https://digitalcommons.usf.edu/gsp/vol15/iss3/8

This Articles is brought to you for free and open access by the Open Access Journals at Digital Commons @ University of South Florida. It has been accepted for inclusion in Genocide Studies and Prevention: An International Journal by an authorized editor of Digital Commons @ University of South Florida. For more information, please contact digitalcommons@usf.edu. 


\title{
Collective Healing: Towards a Conceptual Framework
}

\author{
Garrett Thomson \\ College of Wooster / Guerrand-Hermès \\ Foundation for Peace Research Institute
}

\section{Introduction ${ }^{1}$}

What is healing? In the contexts of post-atrocity and post-genocide, the term healing is metaphorical, and, like all metaphors, it functions by highlighting some similarities at the cost of hiding some differences. ${ }^{2}$ To understand what kind of collective healing practices might be effective after a mass atrocity, we need to comprehend better what constitutes healing. This requires appreciating in what ways the metaphor illuminates and obscures. The question "what is collective healing?" raises entirely different concerns pertaining to the nature of groups, communities, and institutions. In what ways are collective healing processes different from individual ones?

We need clear, well-argued answers to these conceptual questions as a basis for deriving the criteria to evaluate practices. What counts as a good collective healing process? The evaluative criteria delineate what counts as collective healing and define what counts as relevantly good. These evaluative criteria cannot be discovered by empirical investigations alone. It requires a semantic definition of the relevant normative spaces.

The plan is as follows. I shall argue that the concept of healing requires that of being wounded, which in turn requires the idea that some agent performed dehumanizing actions. I will present a new theory of dehumanizing as different kinds of harm and provide a new characterization of healing based on this analysis. The main conclusion of the paper is that there are four different but indispensable aspects of the healing process that are often conflated. Such a conclusion can help us identify the different elements that make collective healing more complete.

\section{Section 1: Preliminaries}

The idea of healing requires that there is something that needs to be healed, and following the metaphorical semantics, the corresponding term is "being wounded." The concept of "healing wounds" has both evaluative and factual aspects: healing is good, and wounds are bad. We need to understand what constitutes the relevant kinds of goodness and badness and distinguish (a) the causes of a wound, (b) what constitutes the wound, and (c) the symptoms of being harmed, concentrating on the nature of the woundedness (i.e. (b). Why is being wounded bad?).

A wound is clearly some form of harm. However, we can contrast being wounded and undergoing material harm. Something can harm one materially without wounding one, and vice versa. In the first case, losing money can cause one harm without constituting being wounded because the latter implies that someone deliberately performed harmful actions. Likewise, having one's money stolen is different from merely losing it, and having one's leg severed by someone is different from losing it accidentally. Being wounded requires that someone performed an act of wounding. In the second case, one could be wounded without being harmed materially, for example, by being shunned from society without being physical deprived. A person could be treated as less than human and thereby wounded, without being harmed materially. Whilst such dehumanization typically involves material harm, and typically causes psychological harm, it needs to be understood as something bad itself, independently of

\footnotetext{
${ }^{1}$ This article is part of the GSP Special Issue 15.3 on Collective Healing. The views expressed in this article belong solely to the author. Due to its technical nature, this article did not undergo the double-blind peer review process.

2 George Lakoff and Mark Johnson, Metaphors We Live By (Chicago: University of Chicago Press, 2003).
} 
these other harms. Being dehumanized itself constitutes a special and grievous kind of harm. In the next section, we shall argue that this harm consists in a violation of one's value as a person. As we will see, this will enable us to characterize trauma. Also, the need for this distinctive kind of harm reoccurs within the notion of justice: justice can be understood as being treated equally as a person. ${ }^{3}$

\section{Section 2: Dehumanization}

"Being wounded" describes being a recipient of an action that dehumanizes or treats one as less than fully human. Dehumanization is not an act of removing the humanity from a person, which is impossible, but rather one of not recognizing it. People can suffer tremendous harm and trauma from natural disasters, but it is quite different to receive them deliberately at the hands of other people. This is, and is perceived as, something they did to us. This merits the phrase "being wounded."

The concept of dehumanizing assumes that persons have a special kind of noninstrumental or non-derivative value, a quasi-Kantian idea best elaborated in two steps. First, material things have only instrumental value, which implies that their valuable nature is entirely derivative of the goals that they serve or promote. Without the relevant ends, the means would have no value at all. Second, the ends themselves have a value that is also derivative, dependent on the value of lives of conscious beings. This second dependence is not instrumental. Rather, the plethora of ends that one has are only valuable in relation to the valuable nature of living as a conscious being. They are only valuable insofar as they relate to the activities, experiences, and processes that compose a life. Thus, we may conclude that the lives of conscious beings have a special kind of non-derivative value. Dehumanization is a violation of or a failure to recognize that value.

The account given so far is Kantian in spirit insofar as it argues for the special value of persons. Kant contended that this value was the foundation of morality, enshrined in the formulations of the Categorical Imperative, the second version of which enjoins people not to treat humanity merely as a means. ${ }^{4}$ However, our account is only quasi-Kantian in at least two respects. First, it is not tied to Kant's metaphysics, such as his transcendental idealism. This is important when we consider group healing. ${ }^{5}$ Second, Kant is trying to define morality. ${ }^{6}$ In contrast, our point is to characterize a special kind of harming, dehumanization, which occurs in violent atrocities. We have not advanced any claims about morality.

These deliberations show that conscious beings and their lives have a special kind of value that is non-derivative. We have not shown that only conscious beings have non-derivative value. Also, we have not taken into account the differences between human and person. Caution is required to avoid speciesism. Standardly, a person is defined as a being that is rational and self-conscious. In this context, "rational" is opposed to non-rational rather than irrational. It is the capacity to respond to reasons. Self-consciousness is the ability to be aware of oneself as "I." Given these definitions, not all persons are humans: other species qualify. Also, not all humans are persons; people in a permanent irreversible coma would not qualify as persons. Moreover, the differences between person and non-person are multi-dimensional and of degree, not a sharp difference of kind as presupposed by Descartes and Kant.7 Human

\footnotetext{
3 Elizabeth S. Anderson, “What is the Point of Equality?,” Ethics 109, no. 2 (1999), $287-337$.

${ }^{4}$ Immanuel Kant, Kant: Groundwork of the Metaphysics of Morals, ed. Mary Gregor (Cambridge: Cambridge University Press, 2012)

${ }^{5}$ Matthew C. Altman, Kant and Applied Ethics: The Uses and Limits of Kant's Practical Philosophy (Chichester: WileyBlackwell, 2011).

${ }^{6}$ Garrett Thomson, On Kant (Belmont: Wadsworth, 2002), Chapter 8.

7 José Luis Bermúdez, The Paradox of Self-Consciousness (Cambridge: The MIT Press, 2000).
} 
embryology and animal intelligence requires these points. ${ }^{8}$ Having mentioned these qualifications, to simplify, we shall treat the terms "human" and "person" as interchangeable.

Dehumanization occurs when a person is treated as an object or as less than a person. The core idea is that a being that has non-derivative value is treated as if she were valuable only derivatively. In this way, dehumanizing constitutes a failure to respect and appreciate the nature of the kind of value of a person. It is a category mistake like the opposite of imbuing a fetish doll with life.

Dehumanizing has several variants such as instrumentalizing, commodifying, objectifying, animalizing, marginalizing, and demonizing. A person is instrumentalized when she is treated as having only instrumental value. Kant expresses this with the second version of the Categorical Imperative. ${ }^{9}$ A person is commodified when she is treated as a commodity, which has only exchange-value. A person is objectified when she is treated merely as an object. Likewise, a person is animalized when she is treated merely as a non-person animal in some regard, for example, when a group is compared to a cockroach or some vermin.10

Although these phenomena are variations on a theme, to understand marginalization and demonization, we need some ancillary ideas. To explain marginalization, the supplementary notion is the equality of all persons. We have explained dehumanization in terms of a person's life being non-derivatively valuable: dehumanization is a failure to respect the person as such. We supplement this with the claim that all persons are equally valuable in this way. We marginalize a person by treating them as less valuable or as inferior. The claim that all people have equal non-derivative value does not mean that one has equal responsibility towards all, but it does mean that there is a good reason not to treat anyone as lesser.

The idea of demonization requires a deeper level. There is an ingrained tendency for us to judge our own actions by the good intentions that we have, which are seemingly obvious to us, and to judge the actions of others by the imperfect consequences of their actions. This is an epistemological asymmetry or double standard. ${ }^{11}$ This is accentuated by reading the bad consequences of a person's action back into her intentions. According to this lopsided hermeneutic, whilst I (or my group) always have good intentions, the others (you, my enemy) have bad intentions as evidenced by your bad actions. ${ }^{12}$ This enemy-making mode of interpretation constitutes a form of dehumanization because it forms one way to treat a person or group as lesser. This kind of dehumanization is demonizing.

With the atrocities of war, dehumanization apparently consists in spurts of violent acts directed towards one group by members of another group. However, dehumanization does not need to be explicitly violent in this way. For instance, the prelude to an atrocity usually consists in protracted propaganda warfare that dehumanizes the other group, portraying them as less than fully human: it usually demonizes, after marginalizing them. Following a violent conflict, the resulting wounds are typically handed down to future generations as feelings of humiliation, victimization, and enmity, which become embedded in a culture and a history, ${ }^{13}$ as narratives that tend to perpetuate the conditions that originally led to the conflict. As we shall see, one can characterize trauma as the experience of the various harms of dehumanization as such, and the traumatic effects of dehumanization can be transmitted transgenerationally.

\footnotetext{
8 Peter Singer, Practical Ethics, 2nd ed. (Cambridge: Cambridge University Press, 1993); Daniel C. Dennett, Kinds of Minds: Towards An Understanding of Consciousness (New York: Basic Books, 1996).

9 Kant, Kant: Groundwork.

${ }^{10}$ David Livingstone Smith, Less Than Human: Why We Demean, Enslave, and Exterminate Others (New York: St. Martins, 2011).

${ }^{11}$ Scherto Gill and Garrett Thomson, Understanding Peace Holistically: From the Spiritual to the Political (New York: Peter Lang, 2019).

12 Alfred Schutz, Collected Papers II: Studies in Social Theory, ed. Arvid Brodersen (The Hague: Martinus Nijhoff, 1976).

13 Victoria Aarons and Alan L. Berger, Third-Generation Holocaust Representation: Trauma, History, and Memory (Evanston: Northwestern University Press, 2017), 42-46.
} 
Violence breeds violence. Without intervention, cycles of violence are a never-ending dehumanization. Violence is a cause of further trauma, but often also a symptom of trauma. ${ }^{14}$

\section{Section 3: Dehumanization as Harm}

Why is being dehumanized a serious harm? The answer pertains to the structure of human well-being. While one can harm a person by stealing her money, such harms are derivative. Thus, we require an account of non-derivative harm to a person's well-being, which has the following four basic dimensions. 15

The first concerns activities. For a person to live well, her life is comprised of processes, activities, and experiences suited to her basic interests, given the relevant socio-cultural contexts. To be deprived of such activities constitutes one dimension of harm. Secondly, for a person to live well, she must appreciate these activities as non-instrumentally valuable. Pain, anxiety, anger, and sadness constitute forms of ill-being along this dimension of awareness. Thirdly, a good life will contain good relationships with other people and with society, and for these to constitute well-being, she must recognize them and engage in them as such. Fourthly, well-being requires appropriate kinds of evaluative self-awareness, meaning that a person is aware of herself as a being of value or dignity.

Notice that this four-fold account of well-being is fundamentally non-hedonistic. It characterizes harm without reducing it to unpleasant feelings. Changes in well-being can occur along any of the four dimensions, and not just the second. They are often counterfactual, and hence do not have to be even felt as a loss or gain.

Being dehumanized constitutes a special form of ill-being along each of these dimensions, which is typically experienced as a trauma. For the purposes of this paper, "trauma" can be defined as the experiential and psycho-physical symptoms or manifestations of these harms of dehumanization. The term refers to the negative ways in which the various harms of dehumanization are experienced as such by the person.

Typically, the harm is especially grave concerning the fourth dimension: one's relationship to oneself. Well-being requires that a person emotionally appreciate herself as having non-derivative value. This recognition is a fundamental form of self-respect that does not depend on what one does or has done. Rather, in the worlds of money and commodities, values are derivative on the valuable nature of a person's life, and one's well-being is partly constituted by one's awareness of this. This evaluative self-perception defines one's relationship with oneself, and harm to it will be expressed as feelings of insecurity, a sense of inferiority, an over-willingness to please others, and a feeling of powerlessness. It will also express itself in the person's relationships with their past and future, such as the erosion of one's sense of oneself as an agent, and through basic self-identifications as a member of a victimized group. At root, these manifest damage to the evaluative self-perception often called dignity, and being dehumanized by others typically causes this kind of harm. These points help define one important strand of the healing process: the appreciative emotional connections to one's dignity.

Dehumanization is also a significant harm along the third dimension: to one's relationships, including one's belonging to a society. Of course, being marginalized and treated as inferior cause harm, but the issue is that they constitute a kind of harm integral to dehumanization. All persons are equally non-derivatively valuable and we all live in societies, so it is a deep harm to be treated as a less than full member of society. Dehumanization is also a harm concerning intergroup relationships. While it causes serious damage to a person's capacities to trust and to have close relationships, dehumanization is itself a harm to the relationships between the groups, as this implies they are degraded. This degradation manifests

\footnotetext{
14 Carolyn Yoder, Little Book of Trauma Healing: When Violence Strikes and Community Is Threatened (New York: Good Books, 2005), 79-81.

${ }^{15}$ Garrett Thomson et al., Happiness, Flourishing and the Good Life: A Transformative Vision for Human Well-Being (London: Routledge, 2020).
} 
as mistrust and hermeneutical stereotyping. The degradation is iterative; it concerns not only how you perceive me and vice versa, but also my beliefs about how you perceive me, and so on.

Concerning the second dimension, dehumanization is harmful insofar as it involves negative emotions that plague a person's consciousness and reduce their capacity to enjoy the valuable activities of life. Sadness, fear, and anger blight our living in the present moment. Dehumanization and its accompanying trauma involve feelings of helplessness, alienation, and humiliation which form part of an unwitting construction of a phenomenal world blighted by self-reinforcing feelings of negativity.

So far, we have characterized the harms of dehumanization of an oppressed group. We can apply the same framework to an oppressor group. Note that, often, the same group occupies both roles: perpetrators often act in dehumanizing ways from a sense their own victimhood, and this double role accelerates the historical cycles of violence. But how is the oppressor group dehumanized and thereby harmed? Such groups tend to have feelings of superiority around historical narratives that apparently justify their privilege, and this constitutes a form of self-dehumanization and harm. Three steps support this view.

First, when one group is marginalized, it is treated as less than equal. ${ }^{16}$ Well-being requires that a person lives in harmony with how things are for the kinds of beings we are. In this context, "how things are" means not only recognizing emotionally that one is nonderivatively valuable, but also appreciating that one is $a$ member of a community of many other people that have the same status. I am a member of a kind, but only one member of this kind: there are others, equally as real and valuable as me. When our emotions close us off to this truth, it constitutes a dehumanizing harm. For this reason, there is a group of illnesses that include being closed in on oneself, being obsessed with one's own self-importance, not being connected to the reality of others. ${ }^{17}$

The second step: to understand well-being, one needs to relinquish the hedonist assumption that, for something to be part of well-being, the lack of it must feel bad; harm does not need to feel bad. The basis for well-being is the constitutive structural features of any human life. These are the dimensions of well-being that form different kinds of noninstrumental value or disvalue. These include the relational, which requires that we relate to others as persons. To live with others, I must appreciate them as persons. This has implications for self-awareness: I must be aware of myself as one among many.

Third, the requirement that we relate to others as persons extends to self-consciousness: we need to be aware of ourselves as one among many. Hence, well-being requires that one regard oneself as one, but only one, member of a special kind of being. We are not asserting that well-being requires one to conform one's actions to a noble and demanding moral principle. Instead, we are affirming that one's well-being constitutively requires that we identify ourselves as one among others, who are equally real as oneself.

In conclusion, what is new about this general theory of dehumanizing? First, it is not a moral theory. It explains dehumanization as a harm and not as a Kantian moral imperative. Second, the theory of harm is multi-dimensional, and it is not hedonistic or preference-based. This has allowed us to characterize dehumanization as a non-reducible variety of different harms, which will enable us to separate different aspects of the healing process in a detailed manner.

\section{Section 4: The Concept of Healing}

The claim that dehumanization is contained in the concept "they did this to us" suggests the seductive idea that the process of healing must be one of humanization, as the opposite of dehumanization. However, this is mistaken because dehumanization is not the removal of the special value of being a person. It is the failure to recognize it. We are already equally persons, non-instrumentally valuable beings. One cannot humanize a human; one cannot restore to a

16 Livingstone Smith, Less than Human, 31-34.

17 Thomson et al., Happiness. 
person her dignity because she had it all along. In this sense, treating healing as a humanization is part of the problem: it assumes that some people are lesser until they are healed. This misleading conception affects practice insofar as it presumes that victims need to be given something, namely a cure. This conception tends to negate the agency of the wounded person in healing. This is a shortcoming of the medical analogy that implicitly compares the person to a patient. Medical language suggests that a traumatized person is a passive patient, who receives treatment from another, who is ideally an expert. Conceived in these terms, the processes tend to undermine themselves: insofar as one regards someone as a passive patient, one is not treating them as a full human person.

The misleading medical suggestion that the wounded person needs to be given something, also permeates the idea that healing is a restoring of wholeness, even though the etymology of "healing" suggests such a conception. ${ }^{18}$ However, since a person is already a whole, the claim that a person needs to have her wholeness restored reinforces the idea that the traumatized are less than wholly human and that something needs to be done by someone else to reestablish this. This is quite different from affirming that they have been treated by others as lesser, and they have a ruptured sense of their worth because of this. Even a dissociation manifested as a personality disorder is a fracture in a person's sense of themselves. It is a dissociation in self-perception that manifests as a personality dissociation as if there were distinct personalities. ${ }^{19}$ In short, healing the wounds concerns cohesive emotional selfperception rather than the bringing together of broken parts.

The opposite of dehumanization is not humanization. The core problem of dehumanization is that the humanity of the person is actively denied or is not recognized. Such treatment is deeply harmful, and this harm is multi-dimensional. For instance, it can lead a person to fail to connect emotionally to her dignity or non-instrumentally valuable nature. Therefore, the opposite of dehumanization is the process of fully recognizing the valuable nature of oneself. This indicates that healing is a holistic educational process of coming to terms with something wounding, which includes overcoming the dehumanizing and working through its harmful psychological effects. van der Hart et al. call this kind of process "realization." 20 The dehumanizing harm and the associated trauma present themselves as unfinished business ${ }^{21}$ that needs to be resolved through processes of realization or coming to terms with what was done to one.

The idea of coming to terms needs explanation. Consider the process of coming to terms with one's own death. Clearly, it is not a simply cognitive exercise restricted to propositional knowledge; it is also an emotional adaptation to a set of truths that are difficult to accept. This means that the process of fully understanding one's death requires an acceptance that may involve feeling fear, sadness, and anger. In this sense, it is cognitive-emotional or holistic. Because it is a painful process, one will have deep resistances to directly confronting one's finitude. Those resistances are fundamentally an unwillingness based on anxieties and phobias, which may involve self-deception. This means that the person has to be willing to come to terms with those resistances as part of the process, and this indicates that the need for meta-cognition, accompanied by considerable patience with oneself. It requires, for instance, understanding that one's resistances serve a protective function so that one is less inclined to judge oneself harshly and punish or persecute oneself in this regard. ${ }^{22}$ This implies that healing relies importantly on the person's willingness to engage with the process. Insofar as it concerns self-perception, it is something that a person does to herself. It is not carried out by someone

\footnotetext{
18 Janina Fisher, Healing the Fragmented Selves of Trauma Survivors: Overcoming Internal Self-Alienation (New York: Routledge, 2017).

19 Onno van der Hart et al., The Haunted Self: Structural Dissociation and the Treatment of Chronic Traumatization (New York: W. W. Norton, 2006), 42.

${ }^{20}$ Ibid., 171-175.

21 Pierre Janet, Psychological Healing: A Historical and Clinical Study (New York: Macmillan, 1925).

22 van der Hart et al., The Haunted Self, 272, 319, 334.
} 
else, such as a therapist or a therapeutic group. It is something that the person actively does herself, albeit with the guidance of a facilitator and a group, even when the healing would not have occurred without those supportive conditions.

Regarding dehumanization, healing processes are not individualistic because the relevant harms are inflicted by another group, and so the healing concerns one's relationship with them, and society in general. The dehumanizing harm is irreducibly social in content, and so is the required healing process. Healing must be understood primarily in terms of a juxtaposition between, on the one hand, emotional self-perception, and self-relations and, on the other, relations to the members of the other group. This juxtaposition does not constitute a contradiction, but rather different facets of the same action.

Any social action has three basic features. The first is the action itself as performed by an agent as an act of the will; the second is the consequences that it has on others and on the agent herself; the third pertains to the social relations that the action instantiates or exemplifies. This general categorization applies to the actions that dehumanize and, as such, it serves to classify the processes of compassionate understanding required for coming to terms with the traumas and harms of dehumanization. The distinction enables us to separate three aspects of any healing processes.

1. Understanding the dehumanizing actions and/or processes;

2. Transcending the personal harmful and traumatic effects of these actions;

3. Repairing the relationships that dehumanizing instantiates.

In the final sections, we will argue that this threefold characterization of the healing process is incomplete because it omits a fourth element pertaining to the structural aspects of social action and the systemic aspects of healing.

Process 1: Directed Towards Understanding the Dehumanizing Acts or Processes Per Se This process helps the persons confront dehumanizing experiences by establishing a framework for the relevant understanding and, in so doing, it initiates a process of meta-cognition: thinking about what one does not fully grasp or want to come to terms with. This framework consists in at least five elements.

First, it must establish a shared space for healing as one in which participants will not be judged, will be actively listened to, and in which their privacy will be respected. It constructs the culture of a safe space. Safety is a precondition of healing. ${ }^{23}$ Second, it establishes a framework in which victims, perpetrators, and others acknowledge the dehumanizing actions in question, and recognize what makes them dehumanizing. Third, it provides an opportunity to better understand why dehumanizing constitutes a serious harm along the four dimensions of well-being. This entails comprehending emotionally what it means to dehumanize, to be dehumanized, and why it is so bad. One way to accomplish this is to help participants acknowledge how dehumanizing others is part of daily life, and how this cuts one off from the experiential reality of the other. This process can help participants transcend guilt.

The final two elements pertain to history. Acts of dehumanization occur as part of a wider historical process and as such they can be understood. However, there is considerable resistance to the idea that we might understand better, for example, the actions of Nazi Germany in the Holocaust. The acts are so deplorable that any attempt to comprehend them may seem like a refusal to condemn them. Nevertheless, any process of dehumanization can be better understood even if this requires moving beyond moral condemnation, albeit without rejecting it. The required understanding is largely historical: anti-Semitism has a long history in Europe, much older than that of romantic German nationalism. Likewise, any conflict has a history characterized by past acts of violence perceived differently by the various sides.

${ }^{23}$ Yoder, Little Book, 87. 
Acknowledging the dehumanization of the history is part of the first process of healing, especially insofar as it involves seeing the history from different points of view, including those of the denials that it generates.

Finally, the need for historical understanding introduces the idea that acts of dehumanization constitute moments in a cycle of violence that will continue into the future until transcended or healed. It involves seeing how the harmful effects of dehumanizing are passed between generations through unintended social learning processes within families and communities. This underscores the need for healing.

Process 2: Directed to the Results of the Dehumanizing Acts

Understanding dehumanizing acts enables a person to reflect better on her own painful experiences; it strengthens the relevant meta-cognitive processes and prepares the person to confront her pain. It prepares the person for the second part of the healing process, which consists in becoming freer from the accumulated pain and other harms of dehumanization. This release consists in coming to terms with past violence and the associated emotions, such as fear, sadness, alienation, and anger. ${ }^{24}$ This process can be compared to mourning. ${ }^{25}$

In this process, the differences between victim and perpetrator are relevant for two reasons. First, the harms suffered by the different groups in a conflict are usually very different. For example, people of African descent in the USA may face the long-term effects of the degradations of slavery, as well as the continued harms of systemic racism. Those of European descent in the USA may face the shame of being the beneficiaries of this past, and the guilt of being complicit in the systemic racism that makes them privileged. ${ }^{26}$ Since these are distinct kinds of harm, the processes of coming to terms with them will be different. This suggests that the two processes should be kept separate. Second, any healing process must feel safe and open to all those concerned. Given that one group is working through its self-alienation as victims and the other through its self-alienation as perpetrators, given that one group is transcending feelings of inferiority and the other assumptions of superiority, given that one is often powerless and the other usually powerful, the dual requirements of safety and openness are in contradiction. ${ }^{27}$ For one group to be open is for the other group to feel unsafe. For this reason, these two requisites can only be met if the healing of the two groups is separate.

\section{Process 3: Directed to the Relationship}

A healing that consisted only of processes 1 and 2 would be radically incomplete. This is because healing requires going beyond the dichotomy of victim and perpetrator. This conclusion follows from the social nature of dehumanization insofar as it is what one group does to another. This means that healing must be relational, and involve a loosening of an antagonistic us versus them.

This requires spaces that allow people to relate to each other intimately and openly. They need to be able to express their pain, fears, and sadness, and to recount difficult experiences without feeling that they are being judged, and in the knowledge that others in the group are listening to them. When people open up and reveal their suffering, it is almost impossible not to be touched emotionally. Suddenly, one is presented with the vivid reality of the experience of another person's experience. This kind of experience has several welldocumented facets. ${ }^{28}$ First, as the members of the groups open their suffering to each other, feelings of empathy overtake negative feelings, such as guilt, anger, and resentment that tend to

\footnotetext{
${ }^{24}$ Michael E. Bernard, ed., The Strength of Self-Acceptance: Theory, Practice and Research (New York: Springer, 2013), 155.

${ }^{25}$ Yoder, Little Book, 94.

${ }^{26}$ David R. Roediger, Colored White: Transcending the Racial Past (Berkeley: University of California Press, 2002).

27 Ofer Grosbard, Israel on the Couch: The Psychology of the Peace Process (Albany: State University of New York Press, 2003), Chapter 2.

${ }^{28}$ James S. Gordon, The Transformation: Discovering Wholeness and Healing After Trauma (New York: HarperOne, 2019), Chapter 18.
} 
fuel ignorance of the lived experience of the other. When it works well, this is a self-reinforcing synergetic group process: any one person undergoing the process supports the others and vice versa. This is one meaning of the term collective healing, and it requires a mixed group. Second, in this process, people's immediate self-identifications shift. The sense of a shared group weakens the divisions between us and them. ${ }^{29}$ Everyone is experienced as more fully human and there is a growing shared sense that we are all people of equal worth. This constitutes a moral ascension that connects with the lived reality of others, pierces the bubble of egoism and widens parochial identities. ${ }^{30}$ Thirdly, this process diminishes the feeling "they did this to us" and "we did this to them but it was not our fault (or it was a long time ago)." While this does not imply negating what happened, it is a process of transcending the roles of victim and perpetrator that carry the potential to recycle the violence accentuated through guilt and blame. ${ }^{31}$ Insofar as this process is successful, people will tend to spontaneously want to ask for forgiveness in a sincere way both as a recognition of the suffering of other persons and as an acknowledgement of responsibility, and not as means to escape their own feelings of guilt..32 This is an important difference: the first expresses a healing in the relationships; the second remains individualistic.

In this type of relational healing, the process cannot be regarded merely as means to a set of ends, such as reconciliation and forgiveness. Such a treatment would ignore the noninstrumental value of the process itself irrespective of ends. The process of people from different sides in a conflict coming together and sharing in a spirit of honesty and openness is valuable in itself. Furthermore, the process embodies the kind of mutual recognition between equal persons as real humans without alienation. Forgiveness as a preset goal would tend to instrumentalize these healing processes. However, it will not instrumentalize them when forgiveness is an unforced expression of a healing of the relationships. If participants sense that the process has a predetermined outcome, then they will feel used and manipulated in a process that should otherwise be deeply intimate such that they feel able to share their fragility.

\section{Some Conclusions}

The first step in our journey based the nature of healing on a new theory of dehumanizing as harm. From this, we concluded that the healing process necessarily has at least three aspects, which have different dynamics and criteria of success. Also, the theory revealed in what ways the medical analogy of healing needs to be replaced with an educational one, understood as holistic and transformative. 33

Now, we shall take a second step because this argument has not yet directly considered the collective nature of healing, nor indeed the fact that dehumanization is often institutional, systemic, and structural.

\section{Section 5: From Collective to Structural}

We need to distinguish the harms associated with a specific event (such as a school shooting or a rape) from those caused by a whole series of events (such as a war). Dehumanizing harms can be caused by a systemic and long-term maltreatment of a person or group and might not be so readily recognized as such compared with a specific dramatic event. ${ }^{34}$

The term collective suggests that the healing in question is of a collection of individual acts. It is worth briefly spelling out why this is misleading in order to purge the tendency to

\footnotetext{
29 Nyla R. Branscombe and Bertjan Doosje, eds. Collective Guilt: International Perspectives (Cambridge: Cambridge University Press, 2004), 37.

30 Gill and Thomson, Understanding Peace Holistically.

31 Branscombe and Doosje, Collective Guilt, Chapter 3.

32 Martin Buber, “Guilt and Guilt Feelings," Psychiatry 20, no. 2 (1957).

${ }^{33}$ Laurie Ann Paul, Transformative Experience (Oxford: Oxford University Press, 2014).

${ }^{34}$ Judith Lewis Herman, Trauma and Recovery: The Aftermath of Violence, From Domestic Abuse to Political Terror (New York: Basic Books, 2015).
} 
conceive dehumanizing as atomic acts performed by individuals, which expunges an adequate conception of its socio-political ramifications. ${ }^{35}$ For this reason, the word "collective" might be replaced by "social." For instance, in an atrocity associated with a war, the violent acts are carried out by one group on another. This is not just a collection of individual acts; as a war between nations or factions, it is ineluctably social. This implies that the meanings of the acts are imbued with the social histories concerning the relations between the groups. ${ }^{36}$ The social meanings of an atrocity require that the acts are something they (a group) did to us (a group), and this means that the shared group histories are integral to the meanings of the atrocity, and thus also to what should count as healing. Thus, individualism hinders the capacity to properly understand social dehumanization. The term "the group" can refer to a nation, an ethnic group, a religious community, so long as they share a persistent sense of sameness with each other. ${ }^{37}$ The sameness is what Vamik Volkan calls "large group identity," which provides belonging and protection to its members. 38

Social dehumanization has some distinctive features. In such a case, the more anxiety and stress the members of a victimized group are going through, the more they will tend to hang on to the large group identity, and the more they share the psychological traits and markers as the result of the dehumanizing harm. This is a self-reinforcing cycle. Likewise (and secondly), if the victimized group suffers from ongoing deprivation, disempowerment, and injustice, this also tends to strengthen the group identities. The symptoms and harms of systemic dehumanization often serve as a reminder of people's internalized large group identity; the reminder is that "it is because of our identity (being Muslim, Jewish, indigenous, African...) that we are suffering as a group." The build-up of such social grievances reinforce the dehumanized relationships between large groups, building an antagonistic us-versus-them, which perpetuates the cycles of violence. Thirdly, these processes are reinforced by the negative hermeneutics in virtue of which we tend to automatically read the intentions of enemy groups as malevolent. ${ }^{39}$ These three reinforcing cycles combine to make healing process 3 increasingly difficult. Remember that process 3 requires that people transcend their local identities insofar they can directly feel the suffering and the shared humanity of the other. The specific dynamics of group identities as defined by structural social conditions render process 3 harder to attain.

This kind of conclusion has been challenged. When Lemkin originally defined the nature of genocide, he did so in terms of groups. ${ }^{40}$ For some writers, this is a problem. The sociologist Rogers Brubaker uses the term "groupism" to specify "the tendency to treat ethnic groups, nations, and races as substantial entities to which interests and agency can be attributed." 41 Groupism or primordialism is accused of two related errors; the first is reifying, that is treating groups as entities, and the second is that of regarding them as homogeneous, ignoring differences within the group. 42

Since we need the idea of a group to understand collective healing, it is incumbent on us to reply to these objections. We will do so by contrasting two types of views that are usually

\footnotetext{
35 Thomas Hübl and Julie Jordan Avritt, Healing Collective Trauma: A Process for Integrating Our Intergenerational and Cultural Wounds (Louisville: Sounds True, 2020).

36 Schutz, Collected Papers.

37 Barbara A. Misztal, Theories of Social Remembering (Maidenhead: Open University Press, 2003), 92-95.

38 Vamik D. Volkan, Psychoanalysis, International Relations, and Diplomacy: A Sourcebook on Large-Group Psychology (London: Karnac Books, 2014).

39 Gill and Thomson, Understanding Peace Holistically.

40 Raphaël Lemkin, Axis Rule in Occupied Europe: Laws of Occupation, Analysis of Government, Proposals for Redress (Washington, D.C.: Carnegie Endowment for International Peace, 1944), 79-95; Howard Ball, Genocide: A Reference Handbook (Santa Barbara: ABC-CLIO, 2010), 9-12.

${ }^{41}$ Rogers Brubaker, "Ethnicity without Groups," in Facing Ethnic Conflicts: Towards a New Realism, ed. Andreas Wimmer et al. (Lanham: Rowman \& Littlefield Publishers, 2004), 35.

42 A. Dirk Moses, "Raphaël Lemkin, Culture, and the Concept of Genocide" in The Oxford Handbook of Genocide Studies, ed. Donald Bloxham and A. Dirk Moses (Oxford: Oxford University Press, 2010), 22-24.
} 
held in opposition to each other, and by arguing that both are mistaken. The first is individualism and the second is groupism. We will carve a position that is neither.

In one extreme form, individualism is the view that only individuals exist. ${ }^{43}$ This confronts the obvious objection that universities, banks, and nation-states also exist, and that these institutions can perform actions such as awarding degrees, making loans, and declaring war. In reply, individualism can turn to the idea that, compared to individual human beings, social institutions are not real because they are derivative. In this modified form, individualism is the view that statements about institutions and social groups can be reduced to claims about individuals. However, in counter-reply, this form of reductionism is also an implausible view because any relevant statement about the behavior or actions of individuals will require mention of their social roles, which will in turn require reference to the relevant institutions. Statements about the social cannot be reduced to relevant claims about the behavior of individuals because there is an ineliminable reference to roles and hence social institutions. ${ }^{4}$

We are tempted to cling to the remnants of individualism even in the face of these severe problems because of the intuition that the alternative looks much worse. The idea that groups and social institutions are entities that have interests quite apart from those of the relevant individual persons looks mildly totalitarian. ${ }^{45}$ For example, it would be worrying to treat the interests of a company as something over and beyond the interests of all its stakeholders, as if those corporate interests could override those of all the stakeholders.

What saves us from this reifying view is Hobbes' idea that the institution can only act through an agent or persona or representative. ${ }^{46}$ The bank needs to hire branch managers to make loans, and it needs executives to hire branch managers, and a board of directors to appoint executives etc. Such assertions do not amount to individualism: it is still the bank or the state that is acting, and its power of agency is not reducible to claims about individuals. Nevertheless, at the same time, the institution cannot act except through individual agents who are performing the roles as defined by the relevant institutions. In short, institutions can act or do things non-reductively and, consequently, individualism is false. However, this does not mean that groupism is true: institutions are not like individual persons insofar as institutions need representatives or role-occupants in order to perform actions. ${ }^{47}$ To avoid reducing institutions, we do not need to reify them.

The conclusion that institutions can perform actions does not support the reifying claim that they have non-instrumental interests beyond those of the relevant individuals. Clearly, an organization or institution can have interests, but those interests are purely instrumental: they pertain to its power and position, its finances and growth. They do not constitute noninstrumental interests such as those that pertain to the living and experiences of a conscious being. Rejecting individualism does not require an implicit totalitarianism.

The conclusion that individualism is erroneous is important for healing in several ways. It allows us to employ the notion of groups in characterizing atrocities and healing, obviating the objections of groupism. Second, often to understand atrocities, we need the concept of structural oppression. This is evident in the case of the North Atlantic slave trade because the racial oppression inherent in slavery has continued past the date of abolition into the contemporary world as structural racism. 48 We need the idea that individualism is false to make

\footnotetext{
${ }^{43}$ Steven Lukes, Power: A Radical View (London: Macmillan International and Red Globe Press, 2005).

${ }^{44}$ Garrett Thomson, "Reificar o Reducir: una poderosa y persistente falsa dicotomía," [Reify or Reduce: A Powerful and Persistent False Dichotomy], Ontología Social: Una Disciplina Frontera, eds. Jaime Ramos Arenas and Carlos Andrés Ramírez (Bogota: Universidad Nacional de Colombia, 2018).

${ }^{45}$ Martin Shaw, "Sociology and Genocide," in The Oxford Handbook of Genocide Studies, ed. Donald Bloxham and A. Dirk Moses (Oxford: Oxford University Press, 2010), 161.

46 Thomas Hobbes, Leviathan, ed. Christopher Brooke (London: Penguin Classics, 2017).

47 Thomson, Reificar o Reducir.

${ }^{48}$ UNESCO Slave Route Project and GHFP, Healing the Wounds of Slave Trade and Slavery (Brighton: GHFP Research Institute, 2020).
} 
sense of the notion of structural dehumanization, which is an important aspect of the relevant healing processes. For instance, any healing process related to the North Atlantic slave trade will need to address the wounds of contemporary structural racism insofar as this is possible. For this claim to even make sense, we need the idea that social structures can dehumanize, an idea that individualism cannot even allow.

The skeptic might persist: How can social structures dehumanize? They are not agents! Social structures refer to the ways relevant institutions are systematically organized in relation to each other, as defined by a set of principles. This means that describing a social structure is not the same as describing the human relationships and actions that occur within that structure. Social structures involve a new emergent characterization, namely the relevant principles and how they shape the relevant institutions, such as the nation-state or corporations. We need antiindividualist to be able to affirm that institutions can perform actions, and that claims about such actions cannot be reduced to statements about individuals. Likewise, anti-individualism allows us to assert that if particular institutions can dehumanize then so can a structured set of institutions.

Given this, it is reasonable to conclude that we can refer to the dehumanizing actions of one group against another without this being understood in terms of reductive individualism and without this requiring some reifying groupism. Now, let us explore the relevance of this for the concept of collective healing, or rather, social healing.

\section{Section 6: The Conditions for Collective Healing}

Earlier we described, among others, two kinds of social harm especially pertinent to dehumanization. Being dehumanized by others will typically damage a person's emotional selfperception that is often called dignity. When this dehumanization is systemic and violent, the damage will be especially grave, but when it is integrated into the person's group selfidentifications, it is even more severe. Second, we mentioned the harm to a person of being marginalized from a society because of dehumanization. This destroys the sense of belonging to a wider community, and this results in the feelings of alienation and anxiety that erode the appreciation of the valuable nature of one's life activities. This effect is especially marked when the marginalization is group-based and when it reflects power relations within a society. We briefly discussed the resulting dehumanizing hermeneutics that demonize a group.

We have now purged the erroneous assumption that dehumanization is necessarily an individual act. It can also be a society-wide process that involves groups, institutions, and even the very structure of a society. However, the healing processes characterized in section 4 remain largely at the level of individuals and groups, and do not take into account institutional and structural dehumanization. In section 5, we defended and characterized the concepts of institutional and structural dehumanization, but we have not yet specified their relevance for healing.

Let us consider the example of racism. Racism can be defined as the treatment of some people, as members of a racial group, as inferior or as less than human or less than equal. It is a phenomenon that has individual, relational, institutional, and structural features, which constitute various kinds of dehumanization. Given this, we have a couple of problems. Our earlier definition of healing was directed towards individual and relation processes; it did not include institutional and structural dehumanization. How might we include them, given that they are not in the control of individual persons?

Additionally, one might ask: Can healing even take place when systemic injustice is prevalent? How can people heal wounds when the stabbing is still occurring? In a social context of systemic dehumanization, can individual and relational healing be effective? In reply, one might contrast two opposing views: the political and the therapeutic. The former argues that healing practices require that there is social justice: there can be no real healing without social justice. The latter is that healing practices are purely psychological, and, because of this, they 
can occur successfully without social justice. Even in social conditions that are oppressive, people can find an integrated sense of themselves. ${ }^{4}$

Neither of these two views is entirely satisfactory. This is because both treat the political and therapeutic, or the structural and individual, as if they were two competing factors on a par. This is an error because social structures refer to the ways relevant institutions are systematically organized in relation to each other, as defined by a set of principles. This means that characterizing a social structure as violent and dehumanizing is not the same as describing the human relationships that occur within that structure. Structure is not reducible to relationships between individual persons. Thus, dehumanizing involves a new element when applied to political-economic structures. This new element is the principles that shape the institutions and the way they dehumanize (such as the nation state, school, the corporation, and the penal system). Consequently, we need to separate two kinds of questions. The most familiar is: how do we improve relations within the existing system? The second is: how do we improve or reform the system? The two questions are very different because they are aimed at different kinds of change.

For this reason, only the relevant actor can directly halt the dehumanizing. Individual dehumanizing needs to be eradicated by the persons who dehumanize; institutional dehumanizing needs to be eliminated by institutions. Therefore, we should not pretend and hope that psychological healing processes alone can shift institutional and structural injustice. Social injustice can be prevented and resisted only through political actions that transform institutions and their relationships, for instance, through legislation and public policy. Thus, we should not presume that individual healing processes can be a substitute for socio-economic reforms. ${ }^{50}$ For example, racial healing cannot replace racial equity. At the same time, the need for the second does not deny the need for the first. In the midst of structural oppression and social violence, people can try to find peace with themselves and to understand each other better. People need to dehumanize each other less, so that they might live better lives, even if the social system remains oppressive and conflictual.

Of course, healing can support social change and vice versa, even if they are not the same. On the one hand, the political actions needed to transform the system become more possible when increasing numbers of antagonistic groups stop dehumanizing each other. This changes the culture. In this way, personal healing can support social reforms, even though it is not undertaken for the sake of such changes. One reason why personal healing should be clearly distinguished from social change, and should not be conceived primarily as a means to the second is that one cannot cure the illnesses of a society through the healing of those who suffer wounds because of those social illnesses! The knifed cannot stop the stabbing. Typically, victims have less power, and their healing cannot carry that social weight.

On the other hand, social reforms can support a personal healing process. For instance, in some circumstances, governmental actions constitute part of a societal-wide healing process. For example, consider a universal declaration that acknowledges the equality of all persons irrespective of ethnicity, nationality, and history; or a public acknowledgment of the suffering caused to peoples of marginalized communities; or a public recognition of the systemic nature of a history of degradation; or a governmental commitment to a set of institutional and policy remedies. These governmental actions would transform the landscape of individual healing processes.

Practically, these points about structural conditions imply that the three healing processes outlined earlier are incomplete: they need to be supplemented by a fourth, one that acknowledges and works on current structural dehumanization and injustice. Process 1 is dedicated to understanding the nature of acts of dehumanization, and part of this is to uncover

\footnotetext{
${ }^{49}$ Joy DeGruy, Post Traumatic Slave Syndrome: America's Legacy of Enduring Injury and Healing (Portland: Joy DeGruy Publications Inc., 2017).

50 David Bloomfield et al., eds., Reconciliation After Violent Conflict: A Handbook (Stockholm: International Institute for Democracy and Electoral Assistance (IDEA), 2003), 81-82.
} 
the relevant history, to show how present injustices and traumas have resulted from past of maltreatment. It is only in the context of some shared historical understanding that antagonistic groups can heal and reconcile. ${ }^{51}$ Now, we are suggesting that one may need an additional fourth element in a healing process: namely, a shared acknowledgement and understanding of how existing social structures dehumanize and an intention to overcome this. Within the safe space created by and for the healing process, existing hierarchical power dynamics should have been suspended and transcended insofar as this is possible. Ideally, within this temporary safe space, the various influences of the structures of exploitation and marginalization have been bracketed. It is because of this that participants are able to attain a shared sense of their common humanity by transcending local self-identifications. But this temporary hallowed state stands in stark contradiction to the massive structural injustice and dehumanization that increasingly characterizes societies. Thus, even a successful healing process is only a temporary respite from such structures.

Given this, the main aim of process 4 is to socially recontextualize healing, to recognize its limitations, and to build a shared understanding of how the group might help overcome oppressive and divisive structures. In this sense, it is defined as a passage from transcending local identities towards solidarity. ${ }^{52}$ It is a phase-transition from relational healing towards the co-construction of some social reforms needed for justice. A fractured society needs to move from enmity to unity. But this is possible only insofar as individual healing processes transform into relational ones, and these relational ones become socially relevant for institutional and social reforms.

\section{Overall Conclusion}

Our initial aim was to give a normative account of the concept of collective healing that would illuminate the healing process. The core is the act of dehumanizing. We specified what is bad about this act. Additionally, we characterized the various kinds of harm that follow from the nature of this action. We defined healing as a holistic overcoming of the act of being dehumanized and as a coming to terms with its harms. This overcoming consists in connecting directly to one's value as a person or one's dignity. To explain "coming to terms," we argued that that any social action has three basic features: the act itself, its harmful consequences, and the social relations it exemplifies. To these, we added a fourth: the structural social conditions that enable the action. On this basis, we argued that the healing process must consist of four very different processes: first, understanding the act itself; second, working through its individual harmful effects; third, transcending the antagonistic social relations; and fourth, acknowledging and trying to overcome the structural conditions. We characterized each of these four processes. We thereby saw how any collective healing process would be incomplete if it did not involve these four elements and would be confused insofar as its did not distinguish them in practice. Healing must encompass the individual, relational, and social, and understand their differences.

\section{Bibliography}

Aarons, Victoria, and Alan L. Berger. Third-Generation Holocaust Representation: Trauma, History, and Memory. Evanston: Northwestern University Press, 2017.

Altman, Matthew C. Kant and Applied Ethics: The Uses and Limits of Kant's Practical Philosophy. Chichester: Wiley-Blackwell, 2011.

Anderson, Elizabeth S. "What is the Point of Equality?." Ethics 109, no. 2 (1999), 287-337.

Ball, Howard. Genocide: A Reference Handbook. Santa Barbara: ABC-CLIO, 2010.

Bar-Tal, Daniel. Shared Beliefs in a Society: Social Psychological Analysis. Thousand Oaks: SAGE, 2000.

\footnotetext{
51 Daniel Bar-Tal, Shared Beliefs in a Society: Social Psychological Analysis (Thousand Oaks: SAGE, 2000), 5-7.

52 Garrett Thomson, "Towards a Theory of Peaceful Relations," in Peacefulness: Being Peace and Making Peace, eds. David Cadman and Scherto Gill (Garðabær: Spirit of Humanity Forum Press, 2017).
} 
Bermúdez, José Luis. The Paradox of Self-Consciousness. Cambridge: The MIT Press, 2000.

Bernard, Michael E., ed. The Strength of Self-Acceptance: Theory, Practice and Research. London: Springer, 2013.

Bloomfield, David, Teresa Barnes, and Luc Huyse, eds. Reconciliation After Violent Conflict: A Handbook. Stockholm: International Institute for Democracy and Electoral Assistance (IDEA), 2003.

Branscombe, Nyla R. and Bertjan Doosje, eds. Collective Guilt: International Perspectives. Cambridge: Cambridge University Press, 2004.

Brubaker, Rogers. "Ethnicity without Groups." In Facing Ethnic Conflicts: Towards a New Realism, edited by Andreas Wimmer, Richard J. Goldstone, and Donald L. Horowitz, 34-52. Lanham: Rowman \& Littleford Publishers, 2004.

Buber, Martin. "Guilt and Guilt Feelings." Psychiatry 20, no. 2 (1957), 114-129.

DeGruy, Joy. Post Traumatic Slave Syndrome: America's Legacy of Enduring Injury and Healing. Portland: Joy Degruy Publications Inc., 2017.

Dennett, Daniel C. Kinds of Minds: Towards An Understanding of Consciousness. New York: Basic Books, 1996.

Fisher, Janina. Healing the Fragmented Selves of Trauma Survivors: Overcoming Internal SelfAlienation. New York: Routledge, 2017.

Gill, Scherto and Garrett Thomson. Understanding Peace Holistically: From the Spiritual to the Political. New York: Peter Lang, 2019.

Gordon, James S. The Transformation: Discovering Wholeness and Healing After Trauma. New York: HarperOne, 2019.

Grosbard, Ofer. Israel on the Couch: The Psychology of the Peace Process. Albany: State University of New York Press, 2003.

Herman, Judith Lewis. Trauma and Recovery: The Aftermath of Violence, From Domestic Abuse to Political Terror. New York: Basic Books, 2015.

Hobbes, Thomas. Leviathan, edited by Christopher Brooke. London: Penguin Classics, 2017.

Hübl, Thomas and Julie Jordan Avritt. Healing Collective Trauma: A Process for Integrating Our Intergenerational and Cultural Wounds. Louisville: Sounds True, 2020.

Janet, Pierre. Psychological Healing: A Historical and Clinical Study. New York: Macmillan, 1925.

Kant, Immanuel. Kant: Groundwork of the Metaphysics of Morals, edited by Mary Gregor. Cambridge: Cambridge University Press, 2012.

Lakoff, George, and Mark Johnson. Metaphors We Live By. Chicago: University of Chicago Press, 2003.

Lemkin, Raphaël. Axis Rule in Occupied Europe: Laws of Occupation, Analysis of Government, Proposals for Redress. Washington, D.C.: Carnegie Endowment for International Peace, 1944.

Livingstone Smith, David. Less Than Human: Why We Demean, Enslave, and Exterminate Others. New York: St. Martins, 2011.

Lukes, Steven. Power. London: Macmillan International and Red Globe Press, 2005.

Misztal, Barbara A. Theories of Social Remembering. Maidenhead: Open University Press, 2003.

Moses, A. Dirk. "Raphaël Lemkin, Culture, and the Concept of Genocide." In The Oxford Handbook of Genocide Studies, edited by Donald Bloxham and A. Dirk Moses, 19-41. Oxford: Oxford University Press, 2010.

Paul, Laurie Ann. Transformative Experience. Oxford: Oxford University Press, 2014.

Roediger, David R. Colored White: Transcending the Racial Past. Berkeley: University of California Press, 2002.

Schutz, Alfred. Collected Papers II: Studies in Social Theory, edited by Arvid Brodersen. The Hague: Martinus Nijhoff, 1976.

Shaw, Martin. "Sociology and Genocide." In The Oxford Handbook of Genocide Studies, edited by Donald Bloxham and A. Dirk Moses, 142-162. Oxford: Oxford University Press, 2010.

Singer, Peter. Practical Ethics, 2nd ed. Cambridge: Cambridge University Press, 1993.

Thomson, Garrett. On Kant. Belmont: Wadsworth, 2002. 
"Towards a Theory of Peaceful Relations." In Peacefulness: Being Peace and Making Peace, edited by David Cadman and Scherto Gill. Garðabær: Spirit of Humanity Forum Press, 2017.

"Reificar o Reducir: Una Poderosa y Persistente Falsa Dicotomía." Ontología Social Una Disciplina Frontera, edited by Jaime Ramos Arenas and Carlos Andrés Ramírez. Bogota: Universidad Nacional de Colombia, 2018.

Thomson, Garrett, Scherto Gill, and Ivor Goodson. Happiness, Flourishing and the Good Life: A Transformative Vision for Human Well-Being. London: Routledge, 2020.

UNESCO Slave Route Project. Healing the Wounds of Slave Trade and Slavery. Approaches and Practices: A Desk Review. Brighton: GHFP Research Institute, 2020.

van der Hart, Onno, Ellert R. S. Nijenhuis, and Kathy Steele. The Haunted Self: Structural Dissociation and the Treatment of Chronic Traumatization. New York: W. W. Norton, 2006.

Volkan, Vamik D. Psychoanalysis, International Relations, and Diplomacy: A Sourcebook on LargeGroup Psychology. London: Karnac Books, 2014.

Yoder, Carolyn. Little Book of Trauma Healing: When Violence Strikes and Community Is Threatened. New York: Good Books, 2005. 